\title{
Ümitvar ahlat klonlarının (Pyrus elaeagrifolia Pallas) in vitro köklenmesi üzerine IBA uygulamalarının etkisi*
}

\author{
Salwa İBRAHIM AHMED OSMAN ${ }^{\circledR 1}$, Hatice DUMANOĞLU ${ }^{\circledR} 2$ \\ ${ }^{1}$ Ankara Üniversitesi Fen Bilimleri Enstitüsü Bahçe Bitkileri Anabilim Dalı Dışkapı, Ankara \\ ${ }^{2}$ Ankara Üniversitesi Ziraat Fakültesi Bahçe Bitkileri Bölümü Dıșkapı, Ankara
}

* Bu makalenin bir kısmı Salwa İbrahim Ahmed Osman'ın Doktora Tez çalışmasına aittir.

Alınış tarihi: 6 Şubat 2020, Kabul tarihi: 19 Mart 2020

Sorumlu yazar: Hatice DUMANOĞLU, e-posta: dmanoglu@agri.ankara.edu.tr

\section{$\ddot{0} \mathbf{z}$}

Ahlat (Pyrus elaeagrifolia Pall.), özellikle kuraklık ve kloroz streslerine dayanıklılığın amaçlandığı armut klon anaç ıslah programları için önemli bir gen kaynağıdır. Bu çalışma, köklenmesi zor olan türler arasında yer alan ahlatta ümitvar dört klonda (Ahlat 32, Ahlat 50, Ahlat 75 ve Ahlat 78) mikro çeliklerin köklenmesi üzerine farklı indol bütirik asit (IBA) dozlarının etkilerini belirlemek amacıyla yapılmıştır. In vitro köklendirme çalışmalarında makro ve mikro element düzeyi 1/2 kuvvetindeki Murashige ve Skoog temel besin ortamı kullanılmıştır. Büyümeyi düzenleyici madde içermeyen bu ortama $\% 2$ sakaroz ilave edilmiş, ortamın pH'sı 5.8'e ayarlanmış ve \%0.7 agar ile katılaştırılmıştır. Kontrol uygulaması dışında mikro çeliklere 250, 500, 1000 ve 2000 ppm IBA, aseptik koşullarda 10 saniye süreyle hızlı daldırma yöntemiyle uygulanmıştır. Kültürler ilk 5 günü tamamen karanlıkta olmak üzere toplam 4 hafta süreyle 16 saat aydınlık koşullarda inkübe edilmiştir. $\mathrm{Bu}$ sürenin sonunda mikro çeliklerde köklenme oranı, köklenmiș mikro çeliklerde köklenme düzeyi ve kallus düzeyi tespit edilmiștir. Çalıșma sonucunda, ahlat mikro çeliklerinde köklenme oranlarının genotiplere ve IBA dozlarına göre önemli düzeyde değiştiği belirlenmiştir. Kontrol grubundaki genotiplerde köklenme meydana gelmemiştir. En yüksek köklenme oranları Ahlat 32'de \%72.5, \%84.0 (500 ve $1000 \mathrm{ppm}$ ), Ahlat 50'de \%90.0 (250 ppm), Ahlat 75'de \%57.5, \%48.0, \%48.0, \%51.4 (250, 500, 1000 ve 2000 ppm), Ahlat 78'de \%92.6, \%85.7 (250 ve $500 \mathrm{ppm}$ ) olarak kaydedilmiştir. Sonuç olarak, köklenme ve kallus düzeyleri açısından 250 ppm ve 500 ppm IBA dozlarının ümitvar ahlat klonlarının mikro çeliklerinin in vitro köklendirilmesi için uygun olduğu belirlenmiştir.

Anahtar kelimeler: Pyrus elaeagrifolia, in vitro, mikro çelik, köklenme, IBA, hızlı daldırma yöntemi

\section{The effect of IBA applications in vitro rooting of the promising wild pear clones (Pyrus elaeagrifolia Pallas)}

\begin{abstract}
Pyrus elaeagrifolia Pall. (wild pear) is an important gene source for pear clone rootstock breeding programs, especially for tolerance to drought and chlorosis stresses. This study was carried out to determine the effects of different indole-3-butyric acid (IBA) doses on the rooting of microcuttings of the four promising clones (Ahlat 32, Ahlat 50, Ahlat 75 and Ahlat 78) of P. elaeagrifolia which is among the species that are difficult to root. For the in vitro rooting studies, Murashige and Skoog basal medium containing half strength of macro and micro nutrients without plant growth regulators was used. This medium was supplemented with $2 \%$ sucrose, pH was adjusted to 5.8 and solidified with $0.7 \%$ agar. Except the control, 250, 500, 1000 and 2000 ppm IBA were applied to micro cuttings by quick-dip method for 10 seconds in aseptic conditions. The cultures were incubated for 4 weeks under 16 hours photoperiod conditions, with the first 5 days in the dark. At the end of this period, the rooting rate, the
\end{abstract}


level of rooting ( 1 = weak, 2 = medium, 3 = good, $4=$ very good $)$ and callus level ( $0=$ no callus, $1=$ small, 2 = medium, 3 = large, 4 = very large in rooted microcuttings were determined. In this study, the rooting rates of microcuttings of $P$. elaeagrifolia changed significantly according to the genotypes and IBA doses. In control, rooting did not occur in any of the genotypes. The highest rooting rates were $72.5 \%$ and $84.0 \%$ with 500 and $1000 \mathrm{ppm}$ in Ahlat 32; $90.0 \%$ with $250 \mathrm{ppm}$ in Ahlat 50; $57.5 \%$, $48.0 \%, 48.0 \%$ and $51.4 \%$ with $250,500,1000$ and 2000 ppm in Ahlat 75; $92.6 \%$ and $85.7 \%$ with 250 and $500 \mathrm{ppm}$ in Ahlat 78. As a result, it was determined that $250 \mathrm{ppm}$ and $500 \mathrm{ppm}$ IBA doses with higher rooting and lower callus levels were suitable for in vitro rooting of the microcuttings of the promising clones of P. elaeagrifolia.

Key words: Pyrus elaeagrifolia, in vitro, microcutting, rooting, IBA, quick-dip method

\section{Giriş}

Meyve türlerinde klon anaç ıslahında köklenme en kritik noktadır. Dünyada, 20. yüzyılın sonlarından itibaren hızla gelişen mikro çoğaltım tekniği ile köklendirmede elde edilen başarılı sonuçlar sayesinde günümüzde meyve türlerinde klon anaç ıslahı çalışmaları çok büyük bir ivme kazanmıştır. Böylece klon anaçların sayısı yüksek düzeylere ulaşabilmiştir. Bununla birlikte köklenme, özellikle zor köklenen bitkilerde hâlâ mikro çoğaltımın en kritik aşamalarından birisi olup başarısızlık ya da düşük başarı durumlarında çok yüksek ekonomik kayıplara neden olabilmektedir (De Klerk, 2002). Mikro çoğaltımda köklenme başarısı üzerine en etkili faktör genotip olmakla birlikte dış koşullar ve uygulamalar diğer önemli unsurlardır (Hartmann ve ark., 2011). Uygun protokollerin geliştirilmesi ile kök oluşumunun güç olduğu genotiplerde de köklenmede başarılı sonuçlar alınabilmektedir. Zor ve kolay köklenme yeteneğine sahip birçok genotipi kapsayan Pyrus türlerinde de mikro çoğaltım çalışmalarında köklenme başarısının genotip ile birlikte köklenmeyi uyarıcı uygulamalara göre değiştiği görülmektedir (Berardi ve ark., 1992, Moretti ve ark., 1992, Baraladi ve ark., 1993, AlMaarri ve ark., 1994, Reed, 1995, Shibli ve ark., 1997, Leite ve ark., 2000, Previati ve ark., 2002, Leite ve ark., 2002, Barros ve ark., 2005, Iglesias ve ark., 2004, Bahri-Sahloul ve ark., 2005, Lucyszyn ve ark., 2006, Quetirio ve ark., 2008, Thakur ve Kanwar, 2008, Sun ve ark., 2009, Haq ve Kaloo, 2010, Saadat ve ark., 2012, Hassanen ve Gabr, 2012, Ertürk, 2013, Rehman ve ark., 2014a, b, Aygun ve Dumanoglu, 2015, Alizadeh ve ark., 2018, Karakeçili ve ark., 2019).

Pyrus türleri içerisinde kurak, kıraç ve soğuk alanlara uyum yeteneği ve kültür çeşitleriyle yüksek aşı başarısı sayesinde armuda anaç olarak kullanılabilecek değerli bir gen kaynağı olan ahlatta (Pyrus elaeagrifolia Pall.) anaç ıslah çalışmaları, özellikle küresel ısınmanın ciddi bir sorun haline geldiği çağımızda sürdürülebilir bir armut tarımı için önemlidir (Özbek, 1978, Lombard ve Westwood, 1987, Bell, 1996, Bell ve Itai, 2011, Dumanoğlu ve ark., 2014). Bu kapsamda tarafımızdan başlatılmış olan anaç ıslah çalışmaları kapsamında seçilmiş ümitvar genotiplerde köklenme başarısının artırılması önemli bir hedeftir. Bu türde önceki çalışmalarda, genotiplere ve çoğaltım tekniğine bağlı olarak köklenme oranlarının \%11.4 ile \%55.0 arasında değiştiği belirlenmiştir (Dumanoğlu ve ark., 1999, Aygun ve Dumanoglu, 2015, Karakeçili ve ark., 2019). Ahlatın mikro çoğaltım çalışmaları kapsamında geliştirilmiş olan bir protokole göre ümitvar ahlat klonları in vitro koşullarda kültüre alınmış ve sürgün çoğaltımları gerçekleştirilmiştir (Aygun ve Dumanoglu, 2015). Ancak bitki üretimlerinin artırılabilmesi için mikro çeliklerinin köklenme oranların yükseltilmesi gerekmektedir. Bu amaç doğrultusunda köklenmede etkili bir oksin olan IBA'nın düşük ve yüksek dozlarının aseptik koşullarda hızlı daldırma yöntemiyle uygulanmasının dört farklı ahlat klonunda kök oluşumu üzerine etkileri araştırılmıştır.

\section{Materyal ve Yöntem}

$\mathrm{Bu}$ çalışmada bitkisel materyal olarak dört ahlat klonu (Ahlat 32, Ahlat 50, Ahlat 75 ve Ahlat 78) (Pyrus elaeagrifolia) kullanılmıștır. Bu klonlar, tarafımızdan 2015 yılında başlatılmış olan armutlar için "ahlat klon anaç ıslah programı" kapsamında Orta Anadolu'nun kireçli, kurak ve kıraç alanlarındaki ahlat popülasyonlarından bodurluk özellikleri (bitki boyu kısa, bir yıllık sürgünleri kısa ve çok sayıda boğumlu, bol çiçek açan ve meyve tutan, gövde kalınlığı az) taşıdığından dolayı seçilmiştir. Bu klonlar, 2018 yılı ilkbahar gelişme periyodunda sürgün ucu kültürüyle in vitro koşullarda kültüre alınmıştır. Köklendirme denemeleri için gerekli olan mikro çelikler 5 hafta arayla yenilenen alt kültürlerden sağlanmıştır. Alt kültürlerde temel besin ortamı olarak, amonyum nitrat düzeyi $1 / 3$ olan Murashige ve Skoog temel 
besin ortamı (Murashige ve Skoog, 1962) kullanılmıştır. Bu ortama $1 \mathrm{mg} / \mathrm{l}$ benziladenin, 0.3 $\mathrm{mg} / \mathrm{l}$ gibberellik asit ve $\% 3$ sakaroz ilave edilmiș, $\mathrm{pH}$ düzeyi 5.8'e ayarlanmış ve $\% 0.7$ agar ile katılaştırılmıștır. Bu kültürlerde mikro sürgünler 250 ml'lik erlenlerde $50 \mathrm{ml}$ besin ortamı üzerine 7'şer adet dikilmiş ve kültürler 16 saat aydınlık (35 $\left.\mu \mathrm{mol} \cdot \mathrm{m}^{-2} \cdot \mathrm{s}^{-1}\right), \quad 8$ saat karanlı fotoperiyodun uygulandığ $25 \pm 1^{\circ} \mathrm{C}$ sicaklıktaki iklim odasında inkübe edilmiştir (Aygun ve Dumanoglu, 2015). Mikro çelikler, alt kültürlerden alınan mikro sürgünlerden steril kabin içerisinde yaklaşık $2 \mathrm{~cm}$ uzunlukta hazırlanmış ve köklendirme denemeleri kurulmadan önce 10-15 gün süreyle büyümeyi düzenleyici madde içermeyen $\% 3$ sakaroz ve $\% 0.7$ agar içeren pH düzeyi 5.8 olan MS ortamı üzerinde aynı koşullarda inkübe edilmiştir. In vitro köklendirme çalışmalarında temel besin ortamı olarak makro ve mikro element düzeyi $1 / 2$ kuvvetindeki MS temel besin ortamı kullanılmıştır. Büyümeyi düzenleyici madde içermeyen bu ortama \%2 sakaroz ilave edilmiş, ortamın pH'sı 5.8'e ayarlanmış ve \%0.7 agar ile katılaştırılmıştır. Köklendirme denemeleri 250 ml'lik cam kavanozlarda $50 \mathrm{ml}$ besin ortamı üzerinde kurulmuştur. IBA solüsyonları \%50'lik etil alkol içerisinde 250, 500, 1000 ve 2000 ppm dozlarında hazırlanmıș ve aseptik koşullarda $0.22 \mu \mathrm{m}$ filtreden geçirilerek steril hale getirilmiştir. IBA solüsyonları steril kabin içerisinde mikro çeliklerin 5 mm'lik dip kısımlarına 10 saniye süreyle hızlı daldırma yöntemiyle uygulanmış ve hemen sonra her bir kavanoza 15 'er adet dikilmiştir. Kültürler ilk 5 günü tamamen karanlıkta olmak üzere 16 saat aydınlık (35 $\mu \mathrm{mol} \cdot \mathrm{m}-2 \cdot \mathrm{s}-1$ ), 8 saat karanlık fotoperiyodun uygulandığı $25 \pm 1^{\circ} \mathrm{C}$ sicaklıktaki iklim odasında toplam 4 hafta süreyle inkübe edilmiştir. Bu sürenin sonunda IBA dozlarının mikro çeliklerde köklenme oranı, köklenen mikro çeliklerde köklenme düzeyi (1 = zaylf, 2 = orta, 3 = iyi, 4 = çok iyi) ve kallus düzeyi ( 0 = kallus yok, 1 = küçük, 2 = orta, 3 = büyük, $4=$ çok büyük) üzerine etkileri tespit edilmiştir.

Deneme, tesadüf parselleri deneme desenine göre her birisinde 15 adet mikro çelik bulunacak şekilde 5 tekerrürlü olarak kurulmuştur. Tüm denemeler iki kez tekrar edilmiştir. Veriler, varyans analizi yöntemi ile Minitab Paket Programı (MINITAB Inc.) ile $F$ testine $(P<0.05)$ göre kontrol edilmiș, ortaya çıkan önemli farklılıklar Duncan testi ile \%5 hata sınırı esas alınarak saptanmış ve farklılıklar harfler yardımıyla belirlenmiştir. Analizlerde yüzde oranların açı değeri karşılıkları kullanılmıştır.

\section{Bulgular ve Tartışma}

$\mathrm{Bu}$ çalışmada, ahlat mikro çeliklerinde köklenme oranlarının genotiplere ve IBA dozlarına göre önemli düzeyde değiştiği belirlenmiştir (Çizelge 1). Kontrol uygulamasında hiçbir genotipte köklenmenin meydana gelmediği çalışmada, en düşük köklenme oranı Ahlat 75 klonunda tespit edilmiştir. Bu klonda köklenme oranı 250, 500, 1000 ve 2000 ppm IBA dozlarında sırasıyla $\% 57.5, \% 48.0, \% 48.0$ ve $\% 51.4$ olarak kaydedilmiş, ancak dozlar arasındaki farklılık istatistiksel anlamda önemli bulunmamıştır. $\mathrm{Bu}$ durum, 1.85-2.14 arasında kaydedilmiş olan köklenme düzeyi için de aynıdır. Ahlat 75 klonunda kallus düzeyi ise 2000 ppm IBA uygulamasında 2.14 ile diğer IBA uygulamalarından (1.13-1.54) önemli düzeyde daha yüksek belirlenmiştir (Çizelge 1, Şekil 1). Kallus düzeyindeki artış mikro çeliklerde kök gelişimi ve bitkiciklerin kalitesi yönünden uygun değerlendirilmemektedir (Mokotedi ve ark., 2000, Gaba, 2005). Diğer ahlat klonlarında en yüksek köklenme oranları ise \%72.5 ile \%92.6 arasında kaydedilmiștir. İstatistiksel anlamda önemli bir farklılıkla köklenme oranları Ahlat 50 klonunda \%90 ile 250 ppm IBA uygulamasında, Ahlat 78 klonunda $\% 85.7$ ve \%92.6 ile 250 ppm ve 500 ppm dozlarında, Ahlat 32 klonunda da $\% 72.5$ ve $\% 84.0$ ile 500 ppm ve 1000 ppm IBA dozlarında en üst seviyesine ulaşmıştır. Ahlat mikro çeliklerinin in vitro köklenmesi konusunda literatürde yer alan iki çalışmadan birisi olan Aygun ve Dumanoglu (2015), araştırmalarında en yüksek köklenme oranını $5 \mu \mathrm{M}$ IBA (1 mg/l) içeren ortam üzerinde \%54.2, hızlı daldırma yöntemi ile $10 \mathrm{mM}$ (2000 ppm) ve $20 \mathrm{mM}$ (4000 ppm) uygulamalarında \%16.7-\%35.3 arasında belirlemişlerdir. Literatürde yer alan diğer bir çalışmada ise Karakeçili ve ark. (2019), yavaş daldırma yöntemiyle (1 saat) $162.6 \mathrm{mg} / \mathrm{L}$ (162 ppm) IBA uygulamasında zor köklenen ahlat genotipinde en yüksek \%25.0 ve daha kolay köklenen genotipte \%54.5 oranlarında köklenme sağlamışlardır.

Ahlatta daha önce yapılmış çalışmaların verileri, bu çalışmada elde ettiğimiz köklenme değerlerinden daha düşüktür. Nitekim bu çalışmamızda köklenme oranları genotiplere göre değişmekle birlikte \%92.6'ya kadar ulaşmıştır. 
Zor köklenen Ahlat 75 klonunda dahi bu oran \%57.5 olarak belirlenmiştir. $\mathrm{Bu}$ bulgular, ahlat mikro çeliklerinin köklenmesinde IBA'in etkin rolüne ve uygulama dozunun genetik yapı ile yakın ilişkisine dikkat çekmektedir. IBA, kök apikal meristeminin boyutlarının düzenlenmesi, kök emici tüylerinin uzunluğu, yan köklerin gelişimi ve adventif köklerin oluşumunu kapsayan kök gelişimi ile ilgili birçok olayda kuvvetli bir etkiye sahiptir (Frick ve Strader, 2018).

Çizelge 1. Ahlat klonlarında mikro çeliklerin in vitro köklenmesi üzerine hızlı daldırma yöntemiyle IBA uygulamalarının etkisi*

\begin{tabular}{|c|c|c|c|c|}
\hline Klon adı & IBA Dozu & Köklenme Oranı (\%) & Köklenme Düzeyi (1-4) & Kallus Düzeyi (0-4) \\
\hline \multirow{5}{*}{ Ahlat 32} & Kontrol & $0.0 \pm 00 \mathrm{~d}^{* *}$ & - & - \\
\hline & $250 \mathrm{ppm}$ & $59.9 \pm 5.0 \mathrm{bc}$ & $2.83 \pm 0.21$ & $0.78 \pm 0.13 \mathrm{c}$ \\
\hline & $500 \mathrm{ppm}$ & $72.5 \pm 6.3 \mathrm{ab}$ & $2.24 \pm 0.27$ & $1.46 \pm 0.14 \mathrm{~b}$ \\
\hline & 1000 ppm & $84.0 \pm 4.8 \mathrm{a}$ & $2.15 \pm 0.23$ & $2.53 \pm 0.26 \mathrm{a}$ \\
\hline & 2000 ppm & $42.6 \pm 10.8 \mathrm{c}$ & $2.48 \pm 0.22$ & $2.85 \pm 0.22 \mathrm{a}$ \\
\hline \multirow{5}{*}{ Ahlat 50} & Kontrol & $0.0 \pm 0.0 \mathrm{c}$ & - & - \\
\hline & $250 \mathrm{ppm}$ & $90.0 \pm 3.2 \mathrm{a}$ & $2.80 \pm 0.19$ & $1.07 \pm 0.12$ \\
\hline & $500 \mathrm{ppm}$ & $59.8 \pm 15.5 b$ & $2.28 \pm 0.51$ & $1.56 \pm 0.22$ \\
\hline & $1000 \mathrm{ppm}$ & $0.0 \pm 0.0 \mathrm{c}$ & - & - \\
\hline & $2000 \mathrm{ppm}$ & $0.0 \pm 0.0 \mathrm{c}$ & - & - \\
\hline \multirow{5}{*}{ Ahlat 75} & Kontrol & $0.0 \pm 0.0 \mathrm{~b}$ & - & - \\
\hline & $250 \mathrm{ppm}$ & $57.5 \pm 7.2 \mathrm{a}$ & $2.11 \pm 0.07$ & $1.13 \pm 0.06 \mathrm{~b}$ \\
\hline & $500 \mathrm{ppm}$ & $48.0 \pm 6.8 \mathrm{a}$ & $2.10 \pm 0.05$ & $1.42 \pm 0.10 \mathrm{~b}$ \\
\hline & 1000 ppm & $48.0 \pm 2.5 \mathrm{a}$ & $1.85 \pm 0.23$ & $1.54 \pm 0.09 \mathrm{~b}$ \\
\hline & $2000 \mathrm{ppm}$ & $51.4 \pm 18.6 \mathrm{a}$ & $2.14 \pm 0.44$ & $2.14 \pm 0.32 \mathrm{a}$ \\
\hline \multirow{5}{*}{ Ahlat 78} & Kontrol & $0.0 \pm 0.0 \mathrm{c}$ & - & - \\
\hline & $250 \mathrm{ppm}$ & $85.7 \pm 4.5 \mathrm{ab}$ & $3.22 \pm 0.14 \mathrm{a}$ & $1.50 \pm 0.07 \mathrm{~b}$ \\
\hline & $500 \mathrm{ppm}$ & $92.6 \pm 2.3 \mathrm{a}$ & $2.43 \pm 0.13 \mathrm{~b}$ & $2.0 \pm 0.13 \mathrm{~b}$ \\
\hline & 1000 ppm & $61.4 \pm 9.2 \mathrm{~b}$ & $1.10 \pm 0.08 \mathrm{c}$ & $2.02 \pm 0.14 \mathrm{~b}$ \\
\hline & 2000 ppm & $18.6 \pm 15.3 \mathrm{c}$ & $1.98 \pm 1.23 \mathrm{~b}$ & $3.25 \pm 0.75 \mathrm{a}$ \\
\hline
\end{tabular}

*Kültürler, ilk 5 gün tamamen karanlık koşullarda inkübe edilmiștir.

${ }^{* *}$ Her klonda Duncan testine $(P \leq 0.05)$ göre aynı harflerin verildiği uygulamalar arasında istatistiksel farklılık bulunmamaktadır.

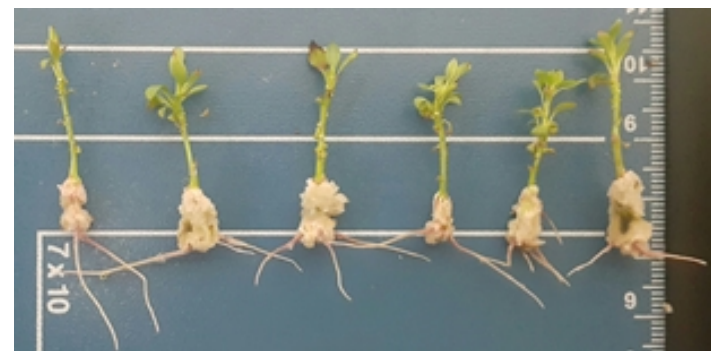

Şekil 1. Ahlat 75 klonunda 2000 ppm IBA uygulaması sonucunda kallus gelişimi

$\mathrm{Bu}$ çalışmada köklenme düzeyi bakımından IBA dozları arasındaki farklılıklar önemsiz bulunurken kallus gelişimi, beklendiği gibi yüksek IBA dozlarında üst düzeylere ulaşmıştır. Yüksek IBA dozlarında köklenme meydana gelmiş olsa dahi iri kalluslu sağlıksız sürgün yapısına sahip bu in vitro bitkiciklerin dış koşullara alışamadığı gözlenmiştir. Çeliklere uygulanan yüksek IBA dozları etilen biyosentezini uyarmakta bu ise absizik asit üretimini tetiklemektedir. Farklı organlara taşınan absizik asit stomaların kapanmasina, etilen ile birlikte yaprakların yaşlanmasına ve sonunda ölmesine neden olmaktadır (Grossmann, 2010, Kilkenny ve ark., 2012, Gehlot ve ark., 2014). Aslında IBA'nın uyardığı etilen mikro çeliklerden kök emici tüylerinin oluşumu için gereklidir (Zhang ve ark., 2019). Ancak, kültürlerde biriken etilen, sürgün sağlığını olumsuz etkilemekte ve bu durum in vitro bitkiciklerin dış koşullara alışmasını güçleştirmektedir (Steinitz ve ark., 2010). Ayrıca yüksek IBA dozları kallus gelişimini uyarırken köklenmeyi engelleyici etkiye sahip olabilmektedir (Gaba, 2005). Nitekim, Aygun ve Dumanoglu (2015) ahlatta in vitro köklendirmede $10 \mathrm{mM}$ (2000 ppm) ve $20 \mathrm{mM}$ (4000 ppm) IBA uygulamalarında çok düşük köklenme değerleri (\%16.7-35.3) ve çok büyük kallus gelişimi belirlemişlerdir.
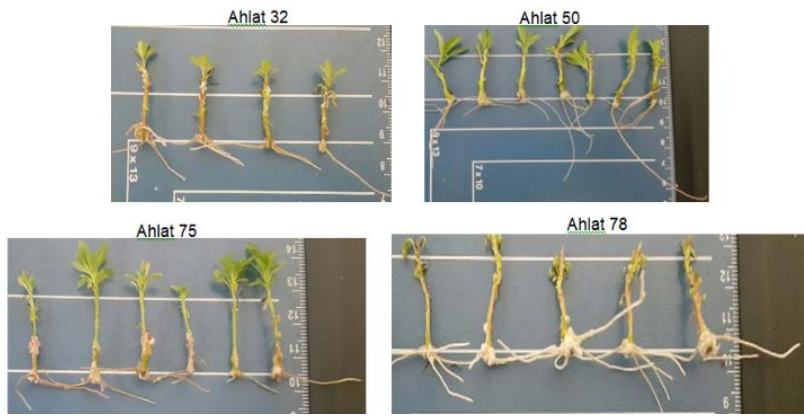

Şekil 2. Ahlat klonlarının hızlı daldırma yöntemiyle 250 ppm IBA uygulaması ile köklendirilmiş in vitro bitkicikleri (ilk 5 gün karanlık uygulanmıştır). 


\section{Sonuç ve Öneriler}

Yüksek köklenme oranları ile birlikte daha iyi köklenme düzeyi ve daha düșük kallus gelișme düzeyinin gözlendiği hızlı daldırma yöntemiyle 250 ppm (Şekil 2) ve 500 ppm IBA uygulamalarının ümitvar ahlat klonlarının mikro çeliklerinin in vitro köklendirilmesinde öne çıktığı belirlenmiştir. $\mathrm{Bu}$ çalışma, dört farklı genotipin incelenerek ahlatta hızlı daldırma yöntemiyle IBA uygulamalarında yüksek dozlar yerine düşük dozların mikro çeliklerin köklenmesi ve sağlıklı in vitro bitkilerin üretimi bakımından çok daha etkin olduğunun ortaya konulması yönüyle literatürde bir ilk olma özelliği taşımaktadır.

\section{Kaynaklar}

Al-Maarri, K., Arnaud, Y., \& Miginiac, E. (1994). Micropropagation of Pyrus communis cultivar "Passe Crassane" seedlings and cultivar "Williams", Factors affecting root formation in vitro and ex vitro. Scientia Horticulturae, 58, 207-214.

Alizadeh, S., Polat, G., \& Dumanoğlu H. (2018). Old Home x Farmingdale 333 armut anacının in vitro köklenmesi üzerine oksin ve polivinil alkol uygulamalarının etkileri. Gaziosmanpaşa Üniversitesi Ziraat Fakültesi Dergisi, 35 (Ek Sayı), 47-53.

Aygun, A., \& Dumanoglu, H. (2015). In vitro shoot proliferation and in vitro and ex vitro root formation of Pyrus elaeagrifolia Pallas. Frontiers in Plant Science, 6 (225), 1-8.

Bahri-Sahloul, R., Ammar, S., Msallem, A., \& Mtar, R. (2005). Micropropagation of three Pyrus rootstocks. Advances in Horticultural Science, 19, 21-28.

Baraladi, R., Bertazza, G., Predieri, S., \& Bregoli, A.M. (1993). Uptake and metabolism of indole-3-butyric acid during the in vitro rooting phase in pear cultivars (Pyrus communis). Acta Horticalturae Plant Growth Regulators, 329, 289-291.

Barros, M.T.F., Hipólito, C.I., \& Baptista, C.G.M. (2005). In vitro rooting of Portuguese pear cultivars (Pyrus communis) in response to changes in auxin induction and dark period treatments. Acta Horticulturae, 671, 631-636.

Bell, R.L., \& Itai, A. (2011). “Pyrus, 147-177”. In, Wild Crop Relatives, Genomic and Breeding Resources (Ed. C. Kole). Springer, Berlin, 247 pp.

Berardi, G., Neri, D., Maiorino, A., \& Adversi, R. (1992). In vitro rooting of Pyrus calleryana. Acta Horticulturae, 300, 181-188.
De Klerk, G. J. (2002). Rooting of microcuttings, Theory and practice. In vitro Cellular \& Developmental Biology Plant, 38, 415-422.

Dumanoğlu, H., Aygün, A., Alay, A., Güneș, N., \& Özkaya, M.T. (1999). Ahlatın (Pyrus elaeagrifolia Pall.) yeşil çeliklerinde köklenme ve sürme üzerine çelik alma zamanı IBA ve putrescine'in etkileri. Turkish Journal of Agriculture and Forestry, 23, 559-565.

Dumanoğlu, H., Çelik, A., Büyükkartal, H.N., \& Dousti, S. (2014). Morphological and anatomical investigations on in vitro micrografts of $\mathrm{OHxF} 333$ / Pyrus elaeagrifolia interstock/rootstock combination in pears. Tarım Bilimleri Dergisi, 20, 269-279.

Erturk, U. (2013). The in vitro rooting performance of pear rootstock 'OHxF 333' in different rooting procedures. Journal of Food, Agriculture \& Environment, 11, 1424-1427.

Frick, E.M., \& Strader, L.C. (2018). Roles for IBA-derived auxin in plant development. Journal of Experimental Botany, 69 (2), 169-177.

Gaba, V.P. (2005). "Plant Growth Regulators in Plant Tissue Culture and Development, 87-99". In, Plant Development and Biotechnology (Eds. R.N. Trigiano \& D.J. Gray). CRC Press, Boca Raton, London, New York, Washington, D.C., 357 pp.

Gehlot, A., Gupta, R.K., Arya, I.D., Arya, S., \& Tripathi, A. (2014). De novo adventitious root formations in mini-cuttings of Azadirachta indica in response to different rooting media and auxin treatments. (Web page, http,//www.sisef.it/ iforest/contents/?id=ifor1189-007 (Date accessed, February 03, 2020).

Grossmann, K. (2010). Auxin herbicides, Current status of mechanism and mode of action. Pest Management Science, 66(2),113-120.

Haq, Z., \& Kaloo, Z.A. (2010). In vitro micro propagation of 'sand pear' Pyrus pyrifolia (Burm. F.) Nakai. Frontiers of Agriculture in China, 4, 358-361.

Hartmann, H.T., Kester, D.E., Davies, Jr.F.T., \& Geneve, R.L. (2011). Plant Propagation (Principle and Practices) (Eighth Edition). Prentice Hall, Boston, 915 pp.

Hassanen, S.A., \& Gabr, M.F. (2012). In vitro propagation of pear Pyrus betulaefolia rootstock. AmericanEurasian Journal of Agricultural \& Environmental Sciences, 12 (4), 484-489.

Iglesias, I., Vilardell, P., Bonany, J., Claveria, E., \& DolcetSanjuan, R. (2004). Micropropagation and field evaluation of the pear (Pyrus communis L.) 'IGE 2002', a new selection of the cultivar Dr. Jules Guyot. Journal of the American Society for Horticultural Science, 129, 389-393. 
Karakeçili, A., Korpayev, S., Dumanoğlu, H., \& Alizadeh, S. (2019). Synthesis of indole-3-acetic acid and indole-3-butyric acid loaded zinc oxide nanoparticles, Effects on rhizogenesis. Journal of Biotechnology, 303, 8-15.

Leite, G.B., Finardi, N., \& Fortes, G.R.L. (2000). Effects of sucrose concentration in culture medium and light intensity on "in vitro" rooting of $\mathrm{OHxF97}$ pear rootstock. Ciencia e Agrotecnologia, 24, 353-357.

Kilkenny, A.J., Wallace, H.M., Walton, D.A., Adkins, M.F., \& Trueman, S.J. (2012). Improved root formation in eucalypt cuttings following combined auxin and anti-ethylene treatments. Journal of Plant Sciences, 7, 138-153.

Leite, G.B., Finardi, N.L., \& Fortes, G.R.L. (2002). Use of vermiculite as a substrate and effect of light on in vitro rooting of pears, cv. Bartlett and clone OHxF97. Ciencia e Agrotecnologia, 26, 977-982.

Lombard, P.B., \& Westwood, M.N. (1987). "Pear Rootstocks, 145-183". In, Rootstocks for Fruit Crops (Eds. R.C. Rom \& R.F. Carlson). A WileyInterscience Publication, John Wiley and Sons, Inc., New York, 494 pp.

Lucyszyn, N., Quoirin, M., Ribas, L.L., \& Sierakowski, R. (2006). Effect of agar, galaktomannan and indolebutyric- acid on in vitro rooting of the pear cultivar 'Durondeau' and apple rootstock cultivar. The Journal of Horticultural Science and Biotechnology, 81, 310-314.

Mokotedi, M.E.O., Watt, M.P., Pammenter, N.W., \& Blakeway, F.C. (2000). In vitro rooting and subsequent survival of two clones of a cold-tolerant Eucalyptus grandis x E. nitens hybrid. HortScience, 35 (6), 1163-1165.

Moretti, C., Scozzoli, A., Pasini, D., \& Paganelli, F. (1992). In vitro propagation of pear cultivars. Acta Horticulturae, 300, 115-118.

Murashige, T., \& Skoog, F., (1962). A revised medium for rapid growth and bioassay with tobacco tissue cultures. Physiologia Plantarum, 15, 473-497.

Özbek, S. (1978). Özel Meyvecilik (Kışın Yaprağını Döken Meyve Türleri). Çukurova Üniversitesi Ziraat Fakültesi Yayınları No, 128. Ankara Üniversitesi Basımevi, Ankara, 485 s.
Previati, A., Da Re, F., Bassi, D., Tagliavini, M., \& Marangoni, B. (2002). Development of protocols for in vitro rooting of advanced selections of Pyrus communis rootstocks. Acta Horticulturae, 596, 485-486.

Quiterio, P.V.B., Traquina, D.M.O., Alves, M.H.L., Pereira, M.J., \& Silva, D.J.M. (2008). In vitro establishment and multiplication of pear rootstocks. Acta Horticulturae, 800, 695-700.

Reed, B.M. (1995). Screening Pyrus germplasm for in vitro rooting response. HortScience, 30, 1292-1294.

Rehman, H.U., Gill, M.I.S., Sidhu, G.S., \& Dhaliwal, H.S. (2014a). Micropropagation of Kainth (Pyrus pashia)-An important rootstock of pear in Northern Subtropical Region of India. Journal of Experimental Biology and Agricultural Sci., 2, 188-196.

Rehman, H.U., Gill, M.I.S., Sidhu, G.S., Dhillon, W.S., \& Bedi, S. (2014b). Micropropagation of Patharnakh (Pyrus pyrifolia (Burm F.) Nakai) pear using explants obtained from forced cuttings. The International Journal of Agricultural Sciences and Veterinary Medicine, 2 (2), 54-65.

Saadat, Y.A., Jokar, L., \& Jahromi, L.S., (2012). In vitro rooting of Pyrus glabra Boiss. microshoots. Iranian Journal of Natural Resources Research, 1, 46-51.

Shibli, R.A., Ajlouni, M.M., Jaradat, A., Aljanabi, S., \& Shatnawi, M. (1997). Micropropagation in wild pear (Pyrus syrica). Scientia Horticulturae, 68, 237242.

Steinitz, B., Barr, N., Tabib, Y., Vaknin, Y., \& Bernstein, N. (2010). Control of in vitro rooting and plant development in Corymbia maculata by silver nitrate, silver thiosulfate and thiosulfate ion. Plant Cell Reports, 29,1315-1323.

Sun, H., Bell, R.L., \& Xin, L. (2009). Effect of polyvinyl alcohol on in vitro rooting capacity of shoots in pear clones (Pyrus communis L.) of different ploidy. Plant Cell Tissue Organ Culture, 99, 299-304.

Thakur, A.T., \& Kanwar, J.S. (2008). Micropropagation of 'wild pear' Pyrus pyrifolia (Burm F.) Nakai. II. Induction of rooting. Notulae Botanicae Horti Agrobotanici, 36, 104-111.

Zhang, D., Liu, C., Yang, Y., Wu, Q., \& Li, Y. (2019). Plant root hair growth in response to hormones. Notulae Botanicae Horti Agrobotanici, 47 (2), 278-281. 